University of the Pacific

Scholarly Commons

University of the Pacific Theses and

Dissertations

Graduate School

2019

\title{
Saudi Arabian Students in Postgraduate Dental Programs: Investigating Factors Associated with Burnout
}

Asiri Amal

University of the Pacific

Follow this and additional works at: https://scholarlycommons.pacific.edu/uop_etds

Part of the Curriculum and Instruction Commons, and the Dentistry Commons

\section{Recommended Citation}

Amal, Asiri. (2019). Saudi Arabian Students in Postgraduate Dental Programs: Investigating Factors Associated with Burnout. University of the Pacific, Thesis. https://scholarlycommons.pacific.edu/ uop_etds/3641

This Thesis is brought to you for free and open access by the Graduate School at Scholarly Commons. It has been accepted for inclusion in University of the Pacific Theses and Dissertations by an authorized administrator of Scholarly Commons. For more information, please contact mgibney@pacific.edu. 


\title{
SAUDI ARABIAN STUDENTS IN POSTGRADUATE DENTAL PROGRAMS: INVESTIGATING FACTORS ASSOCIATED WITH BURNOUT
}

\author{
By
}

Amal Asiri

\author{
A Thesis Submitted to the \\ Graduate School \\ In Partial Fulfillment of the \\ Requirements for the Degree of \\ MASTER OF ARTS
}

Gladys L. Benerd School of Education

Curriculum and Instruction

University of the Pacific

Stockton, California 
SAUDI ARABIAN STUDENTS IN POSTGRADUATE DENTAL PROGRAMS: INVESTIGATING FACTORS ASSOCIATED WITH BURNOUT

By

Amal Asiri

APPROVED BY:

Thesis Advisor: Rachelle Kisst Hackett, Ph.D.

Committee Member: Marilyn Draheim, Ph.D.

Dean of Benerd College: Patricia Campbell, Ph.D. 


\title{
SAUDI ARABIAN STUDENTS IN POSTGRADUATE DENTAL PROGRAMS: INVESTIGATING FACTORS ASSOCIATED WITH BURNOUT
}

\author{
Abstract \\ By Amal Asiri \\ University of the Pacific
}

2019

Burnout related to emotional and physical study or work demands affects an individual's performance and well being. This study focused on Saudi Arabian dental residents studying in the United States and the United Kingdom who are faced with many challenges in pursuit of a higher education degree. A survey including demographic and MBI questions was distributed to assess this population's level of burnout. The Maslach Burnout inventory (MBI) was has been widely used in the literature to assess three components of burnout: emotional exhaustion (EE), depersonalization (DEP), and (diminished) personal accomplishment (PA). Potential predictors of burnout level, tested for statistical significance, included: (1) country (US vs UK), (2) hours of work, (3) sponsorship status, (4) marital status (5) gender and (6) prior work experience. Using multiple regression analyses, those found to predict EE included hours of work, sponsorship status, and gender. Only gender was found to predict PA. None of the variables were predictive of DEP. Moreover, after controlling for the demographic variables, the country where studying did not help account for level of burnout. Limitations of the study, implications for practice and suggestions for further research are offered in the discussion. 


\section{TABLE OF CONTENTS}

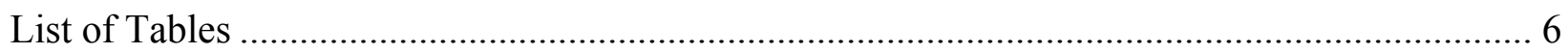

Chapter 1: Introduction .................................................................................................... 7

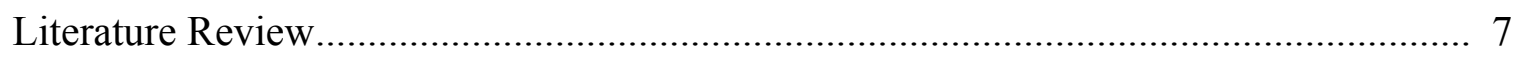

Research Questions ...................................................................................... 11

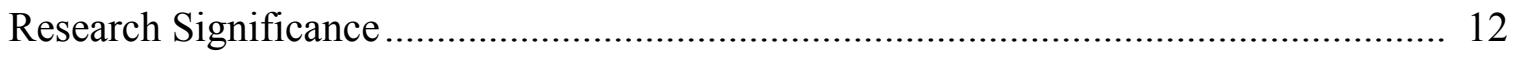

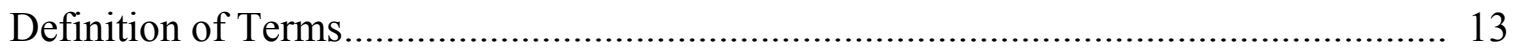

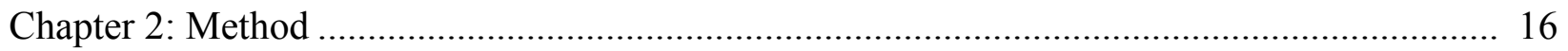

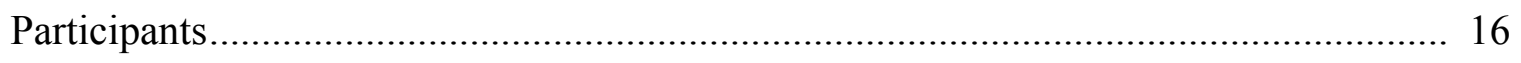

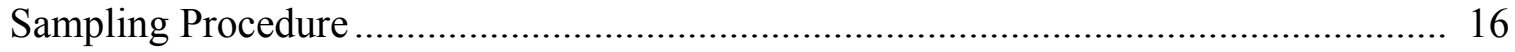

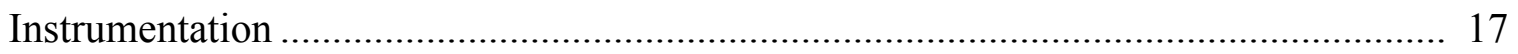

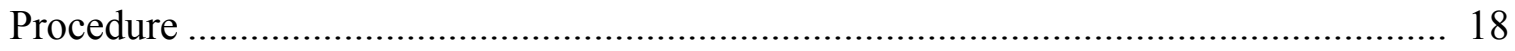

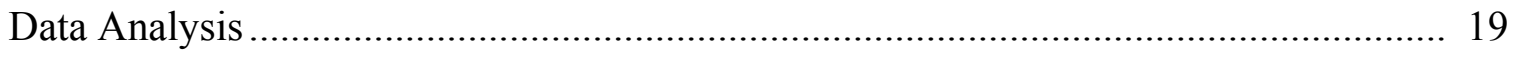

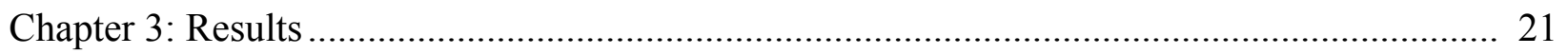

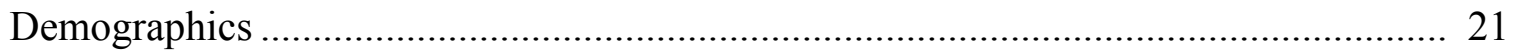

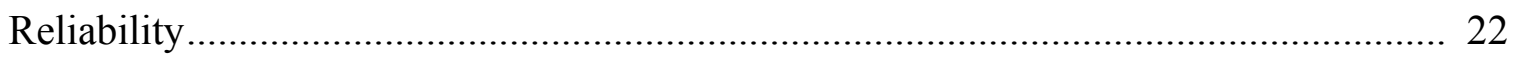

Results Related to Research Question One.................................................................. 22

Results Related to Research Questions Two and Three .......................................... 24

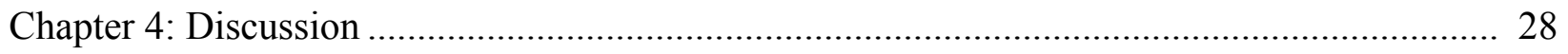

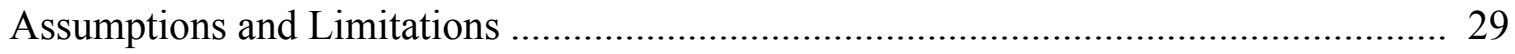

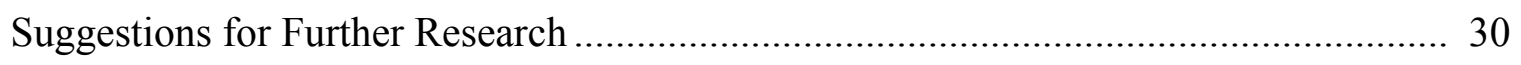

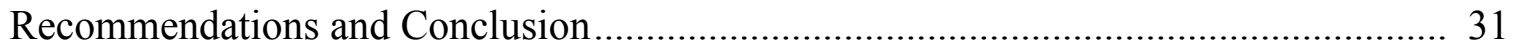




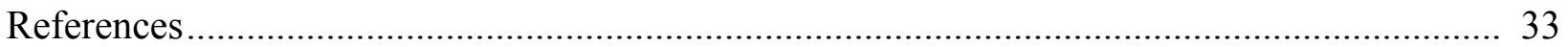

Appendices

A. Online Survey Consent Form...................................................................... 36

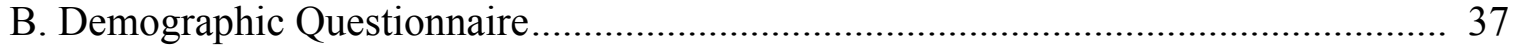




\section{LIST OF TABLES}

Table

1. Breakdown of Dental Studies Timelines According to Location .............................. 15

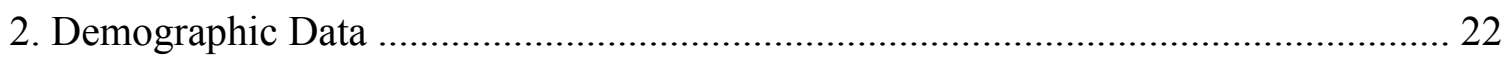

3. Descriptive Statistics and Zero Order Correlations ............................................... 23

4. Sequential Multiple Regression Results Predicting Maslach Burnout Inventory (MBI) Emotional Exhaustion Subscale Scores ...................................................................... 25

5. Sequential Multiple Regression Results Predicting Maslach Burnout Inventory (MBI) Depersonalization Subscale Scores ......................................................................... 26

6. Sequential Multiple Regression Results Predicting Maslach Burnout Inventory (MBI) Personal Achievement Subscale Scores ............................................................ 27 


\section{CHAPTER 1: INTRODUCTION}

\section{Literature Review}

Dental students experience high levels of stress due to the nature of their studies and profession. In the US, a dental student typically spends 3-4 years in dental school following a 34 year bachelor's degree in a related major. In Saudi Arabia, dental school is a 5-year commitment preceded by one preparatory year and ending with one year of internship in public clinics. After passing licensure exams and graduation, some graduates choose to pursue higher education. They compete for acceptance in a variety of postgraduate dental specialty programs where they continue their studies for a few more years. The dental curriculum demands intense memorizing of detailed information across an array of disciplines. Requirements include dental laboratory duties, managing of a variety of routine and unpredictable clinical situations, and multiple written, clinical and licensing examinations throughout dental school years. Numerous studies have indicated that the rigorous training requisites, as well as the span of competencies across clinical, theoretical, and interpersonal requirements, increase rates of stress and burnout in postgraduate dental students (Ahmad et al., 2017; Andre, Pierre \& McAndrew, 2017; Elani, et al., 2014; Divaris, Lai, Polychronopoulou, Eliades, \& Katsaros, 2012; Murphy, Gray, Sterling, Reeves \& DuCette, 2009). Furthermore, there has been an increase in the number of international dental students in postgraduate programs, in which international students can experience additional stressors relating to socio-cultural adjustment, self-efficacy, educational gaps, and other challenges (Assael, 2017; Yusoff, 2011).

Stress is a broad term that can be defined in several ways, though it generally pertains to an individual being overburdened or pressured by the requirements of a given environment, to the 
point where well being is compromised (Ahmad et al., 2016; Elani et al., 2014). Burnout was defined by Maslach and Leiter (2016) as "a psychological syndrome emerging as a prolonged response to chronic interpersonal stressors on the job" (p. 103). Persistent exposure to stress can lead to burnout, which involves work or school-related exhaustion and disengagement (Divaris et al., 2012). Studies have found that in addition to the workload itself, dental students experience fatigue, chronic sleep deprivation, an increased likelihood of being on-call, as well as stressors relating to debt accrued from the high costs of education, and unsteady financial standing (Vinson et al., 2016).

Studies have shown that stress perceived by dental students increases, on average, as students progress in dental school, with seniors reporting higher stress and burnout compared to first and second year dental students (Elani et al, 2014). A study by Harrison, Shaddox, Garvan, \& Behar-Horenstein (2016) employed a sample of 334 students at a U.S. dental school ranging from first to fourth year enrollment. Participants were assessed with the Perceived Wellness Survey, the Mental Health Inventory, and the Medical Outcomes Study Social Support Survey. The results indicated that first-year students reported less social support, and that Asian and Hispanic students indicated less happiness and mental well being compared to the other ethnic subgroups. Notably, whether students were international was not factored in this study. The researchers suggested the need for more well-being support in dental programs to address varying student needs (Harrison, 2016). As dental students are increasingly enrolling in clinical and non-clinical specialty post-graduate programs, either soon after graduation or elsewise during their career, added stressors can hinder well being (Assael, 2017).

While stress and burnout related to the study and practice of dentistry in the predoctoral level has been widely studied, the literature is relatively sparse when it comes to stress in post- 
graduate dental students and residents. Furthermore, literature that specifically assesses international students in postgraduate dental programs is lacking. The average length of a post graduate program is 2-3 years depending on sought credentials and specialty. Programs requirements vary in different countries, and coping mechanisms also vary across different cultures. Divaris et al. (2012) assessed 99 students in a postgraduate dental program in Greece, including clinical, non-clinical, and PhD students. The Graduate Dental Environmental Stress questionnaire was administered to measure stress, and the Maslach Burnout Inventory measured burnout, specifically on the scales of personal accomplishment, emotional exhaustion, and depersonalization. On all three scales of the MBI survey, there was a positive correlation of perceived stress and burnout where most of the sample (44\%) were deemed burnout cases on the emotional exhaustion scale, followed by personal accomplishment (38\%) and depersonalization (13\%). Furthermore, perceived stress was prominent among clinical students compared to nonclinical and PhD programs (Divaris et al., 2012). Another study by Divaris, Polychronopoulou, Taoufik, Katsaros, \& Eliades (2012) assessed stress and burnout in Swiss dental residents applying the same instruments and found that insufficient leisure time, as well as curriculum and research requirements, were among the top stressors. The specific requirements in a dental program have considerable effects on students' capacity to take on the workload, cope with stress, and reduce risks of burnout.

To compare stress and burnout in undergraduate and postgraduate dental students, a study by Nettam, Mandava, SankarSingaraju, Ganugapanta, \& Yelchuri (2018) assessed 285 students across five regions in India. The questionnaire to measure stress was formulated by the International Stress Management Association including the Maslach Burnout Inventory. With a response rate of $71 \%, 142$ participant responses were included in the analysis. Results indicated 
no statistical significance correlating stress and burnout in undergraduate students; however, there was a significant correlation between stress and burnout among postgraduate orthodontic students. Emotional exhaustion and depersonalization were positively correlated with perceived stress measured by the International Stress Management Association questionnaire, as also supported by Divaris et al., 2012, using the Graduate Dental Environment Stress (GDES). However, personal achievement was negatively correlated with burnout (Nettam et al., 2018). Studies addressing stress and burnout in the Saudi dental residents population are especially lacking or limited to dental residents in the same specialty or within one institution. A study by Al-Sowygh (2013) assessed perceived stress among 425 undergraduate dental students at a Saudi Arabian dental program with the Dental Environmental Stress questionnaire and found that clinical requirements correlated with the highest stress levels, particularly among fourth and fifth-year students. Notably, "social stressors" and "performance pressure" were heightened among married students compared to single students (Al-Sowygh et al., 2013). However, a study by Al-Shayea (2014) assessed perceived anxiety, depression, and stress among postgraduate orthodontic students across three institutions in Saudi Arabia. The researchers found that married students, and students over age 30, indicated lower levels of anxiety, though stress was persistent across all categories and institutions. This study employed the Depression Anxiety Stress Scale to a sample of 79 students, of which $51.9 \%$ indicated moderate stress levels (Al-Shayea, 2014). This indicates the general pervasiveness of stress in postgraduate programs, contrary to more varied results when assessing undergraduate dental students. Saudi Arabian dental residents studying abroad potentially undergo added stress due to relocating to a new country and culture and moving away from family and home for a prolonged period of time. The aim of this study is to assess burnout and stress levels in Saudi Arabian dental residents enrolled 
in dental specialty postgraduate programs in the United Kingdom and the United States. Furthermore, this assessment will provide data for comparison between MBI means of dental residents and medical professionals. This analysis was conducted to shed some light on possible contributory factors that residents might want to take into consideration when planning to study abroad.

\section{Research Questions}

This research will address the following questions: (1) What level of burnout, on average, do Saudi Arabian students enrolled in postgraduate programs report as measured by the emotional exhaustion, depersonalization, and (diminished) personal accomplishment subscales of the Maslach Burnout Inventory? (2) What proportion of variation in levels of burnout among Saudi Arabian students enrolled in postgraduate programs is accounted for by the set of predictors which includes: country where studying, hours of work, being sponsored or not, marital status, and prior work experience? (3) Which of the following predictors accounts for unique variation in levels of burnout among these students? The predictors are (1) country (US vs UK), (2) hours of work, (3) sponsorship status, (4) marital status (5) gender and (6) prior work experience. These question will be assessed with a quantitative comparative research design assessing Saudi students enrolled in postgraduate dental programs in the UK and the US using the Maslach Burnout Inventory - Human Services Survey for Medical Personnel (MBI-HSS MP), which is a variation of the MBI tool adapted for medical personnel to measure burnout by addressing three scales: (1) feelings of emotional exhaustion due to work duties, (2) depersonalization measuring lack of sympathy and impersonal attitudes toward patients, (3) personal accomplishment measuring feelings about success and achievement related to the profession (Mind Garden, 2018). 


\section{Research Significance}

Program designs have a significant impact on stress and burnout in postgraduate dental students, and studies indicate that more individualized support for students is needed to reduce stress and burnout (Ahmad, et al., 2017). Different approaches have been applied in an effort to reduce risks of stress and burnout. Ahmed, et al (2017) compared a case-based curriculum and a subject-based curriculum for fifth and sixth-year dental and medical students at Kuwait University and found the case-based format correlated with higher stress levels. Some of the leading sources of stress were related to inconsistent feedback from varying instructors, challenges in effective communication with instructors, and workload amount (Ahmad, et al., 2017). Factors relating to inconsistent feedback, communication challenges are likely to be heightened for international students, in addition to gaps in knowledge and standards in U.S. programs compared to the home country (Assael, 2017). The American Dental Education Association specifies guidelines for robust learning environments for diverse students, as well as measures to address linguistic and cultural backgrounds (ADEA, 2018). However, it is unclear what measures are generally applied to address stress in postgraduate programs. To the researchers' knowledge, there has yet to be a study comparing the stress and burnout among a specific international population in postgraduate dental programs in the United States and the United Kingdom. The study was designed to inform Saudi students about possible predictors of burn out when planning on studying abroad and can also guide U.S. and U.K. postgraduate programs in regard to addressing stress and burnout considerations for international students. 


\section{Definition of Terms}

Burnout: According to Maslach and Leiter (2016), burnout is a psychological syndrome emerging as a prolonged response to chronic interpersonal stressors on the job. The three key dimensions of this response are an overwhelming exhaustion, feelings of cynicism and detachment from the job, and a sense of ineffectiveness and lack of accomplishment.

Stress: According to Baum (1990), stress is an uncomfortable emotional experience accompanied by predictable biochemical, physiological and behavioral changes.

Undergraduate dental student: Students enrolled in a dental school.

Postgraduate dental student: Students who graduated from a dental school awarding a dental degree, who successfully passed licensure exams and are enrolled in a higher education specialty program. These students are referred to, as "residents" when the type of postgraduate program they are enrolled in requires a clinical residency.

Clinical postgraduate dental specialty programs: Those programs with a heavy focus on the clinical procedures of a certain branch in dentistry. The postgraduate students enrolled in this type of program are referred to as residents. These programs typically require residents to diagnose and treat a vast number of patients throughout the duration of the program. They award graduates degrees in the clinical specialties of dentistry, e.g., orthodontics, endodontics, periodontics, etc.

Non-clinical postgraduate dental specialty programs: Those programs with less focus on direct patient-doctor interactions. They vary in nature and requirements according to the field of study. These programs award degrees in the nonclinical specialties of dentistry, e.g., public health and community dentistry, oral biology and biomaterials...etc. This term also potentially 
includes non-clinical degrees in clinical specialties, e.g., Doctor of Philosophy degrees $(\mathrm{PhD})$ in endodontics.

Timeline of dental studies in Saudi Arabia:

Undergraduate dental student $\rightarrow$ intern $\rightarrow$ licensure exam $\rightarrow$ dentist $\rightarrow$ postgraduate dental student

\section{Timeline of dental studies in the United States:}

Pre-dental student $\rightarrow$ dental student $\rightarrow$ Licensure exams $\rightarrow$ dentist $\rightarrow$ postgraduate dental student

\section{Timeline of dental studies in the United Kingdom:}

Undergraduate dental student $\rightarrow$ Foundation dental training $\rightarrow$ licensure exam $\rightarrow$ dentist $\rightarrow$ postgraduate dental student

* For the sake of simplifying, the term undergraduate dental student is used to include all dental students pre-graduation from dental school regardless of location. 
Table 1

Breakdown of Dental Studies Timelines According to Location

\begin{tabular}{|c|c|c|c|c|}
\hline Country & $\begin{array}{l}\text { Pre-dental } \\
\text { school }\end{array}$ & $\begin{array}{l}\text { Dental } \\
\text { School }\end{array}$ & Licensure exams & $\begin{array}{c}\text { After } \\
\text { graduation } \\
\text { options }\end{array}$ \\
\hline $\begin{array}{l}\text { Saudi } \\
\text { Arabia }\end{array}$ & NA & $\begin{array}{c}6 \text { years }+ \\
1 \text { year } \\
\text { internship }\end{array}$ & Saudi Licensing Exam (SLE) & $\begin{array}{c}\text { Practice } \\
\text { dentistry } \\
\text { and/or apply } \\
\text { for a } \\
\text { postgraduate } \\
\text { specialty } \\
\text { program } \\
\end{array}$ \\
\hline $\begin{array}{l}\text { The } \\
\text { United } \\
\text { States }\end{array}$ & $\begin{array}{c}\text { Pre-dental } \\
\text { bachelor's } \\
\text { degree }\end{array}$ & $3-4$ years & $\begin{array}{c}\text { The National Board Dental Examination } \\
\text { (NBDE) + one of the following exams } \\
\text { depending on the desired location of } \\
\text { practice: } \\
\text { The Central Regional Dental Testing } \\
\text { Service (CRDTS), Council of Interstate } \\
\text { Testing Agencies, Inc. (CITA), the } \\
\text { Commission on Dental Competency } \\
\text { Assessments (CDCA) [formerly the } \\
\text { North East Regional Board of Dental } \\
\text { Examiners, Inc./NERB], Southern } \\
\text { Regional Testing Agency (SRTA), and } \\
\text { Western Regional Examining Board } \\
\text { (WREB) }\end{array}$ & $\begin{array}{c}\text { Same as } \\
\text { above }\end{array}$ \\
\hline $\begin{array}{c}\text { The } \\
\text { United } \\
\text { Kingdom }\end{array}$ & NA & $\begin{array}{c}5 \text { years }+ \\
1 \text { to } 2 \\
\text { years of } \\
\text { dental } \\
\text { foundation } \\
\text { training }\end{array}$ & License in Dental Surgery (LDS) & $\begin{array}{c}\text { Same as } \\
\text { above }\end{array}$ \\
\hline
\end{tabular}




\section{CHAPTER 2: METHOD}

\section{Participants}

The target population is Saudi Arabian dental residents enrolled in UK-based and USbased post graduate programs in the following clinical specialties: endodontics, fixed and removable prosthodontics, oral and oromaxillofacial surgery, orthodontics, oral medicine, operative and restorative dentistry, advanced education in general dentistry, oral radiology and pedodontics and periodontics. These specialties were selected due to their clinical nature with repeated resident-patient interactions. The programs award graduates either a certificate of advanced graduate study (CAGS) or a Master of Science degree (MS, MSc) upon completion. All programs require residents to be proficient in the English language as indicated by their TOEFL $^{\circledR}$ or IELTS ${ }^{\circledR}$ scores.

\section{Sampling Procedure}

The sampling method used is the non-probability quota sampling technique. Although ideal, a stratified random sample from the population is not feasible. Based on a power analysis using the software $\mathrm{G}^{*}$ Power, it was determined that to detect a small-medium effect $\left(f^{2}=.09\right)$, a sample size of 158 is needed $(\alpha=0.05$, power $=.80$, \# of predictors $=6)$. Given the main focus of this study being the comparison between residents in two countries (i.e., UK and USA), the minimum number of participants desired was 79 participants for each country. The G*Power software can be downloaded without cost from http://www.psycho.uniduesseldorf.de/abteilungen/aap/gpower3/. As it turned out, the sample size obtained was just 87 cases with complete data (from both countries combined), and given the $R^{2}$ values obtained (which were translated into $f^{2}$ values of $.23, .02$, and .08), the power was $.91, .12$, and .43 for the 
regression models predicting EE, DEP, and PA, respectively. This limitation to statistical conclusion validity will be noted in the discussion.

\section{Instrumentation}

To address the research questions, the criterion variables are emotional exhaustion, depersonalization and professional accomplishment; the control variables are hours of work per week, marital status, gender, prior work experience, and sponsorship status; and the predictor variable is country.

The survey starts with an informed consent page followed by the first part of the survey, which includes demographic questions regarding program location, age, gender, marital status and family living arrangements. Other questions address specialty program type and length, resident position/year, hours of work per week, sponsorship status and work experience prior to joining the program.

To assess perceived stress and burnout, the English version of the Maslach Burnout Inventory Human Services Survey for Medical Personnel MBI-HSS (MP) was distributed to participants via a web link. According to Maslach, Jackson, Leiter, Schaufeli, \& Schwab (1981), sufficient levels of stability estimates and internal-consistency reliability estimates (Cronbach's alpha) are reported for the three MBI-HS scores from a broad sample of workers in professions related to human-services. Cronbach's alphas were $.90, .79$, and .71 for Emotional Exhaustion, Depersonalization, and Personal Accomplishment, respectively. Multiple studies were cited in which test-retest coefficients for the three scale scores were reported for a variety of samples; for example, over a few weeks (.82, .60; and .80 , respectively); three months $(.75, .64$, and .62 , respectively); and up to one year $(.60, .54$, and .57 , respectively). 
The MBI section is the second part of the survey, which contains 22 items to assess burnout on the three identified scales: emotional exhaustion, depersonalization and professional accomplishment. Participants will be asked to rank item responses on a seven-point Likert scale where 0 means "never", 1: "a few times a year or less", 2: "once a month or less", 3: "a few times a month", 4: "once a week", 5: "a few times a week" and 6: "every day". Drafts of the consent form and the demographic part of survey are attached within the appendix. However, the publisher of the MBI part does not allow the items to be disclosed.

\section{Procedure}

Approval from the institutional review board (IRB) was obtained on 2/27/2019 with protocol \#19-53. Contact was made with informal representatives of the Saudi Arabian dental residents in the US and the UK, given their network connections with Saudi Arabian dental residents who are enrolled in a variety of dental programs in both countries. The two representatives filled out the survey as a pilot study sample and reported feedback about phrasing and question options that were taken into account. The surveys were revised and adjustments were made as needed. The two representatives handed out paper recruitment flyers to residents within both of their schools and sent out emails with the flyers attached to acquaintance residents in other schools. These flyers invited potential participants to provide the representatives with their e-mail addresses for the online survey link to be sent out to. The flyers included assurance statements about the anonymous and voluntary nature of the survey. Once, residents responded to the flyer in person or by email by providing their preferred email address, the email addresses were added to a list of recipients on the Survey Monkey website and the survey link was forwarded to the list through the website itself. Once they received the link via email, clicking on it takes the respondent to the consent form page first. Reading and signing the consent by 
clicking on the appropriate button was mandatory to view the survey questions. Otherwise, the link automatically redirected responders to exit the survey. The anticipated response was $80 \%$. However, due to low participation rate, contact with prominent social media figures in the Saudi dental field on Twitter was initiated. These influencers have many followers who are mostly dental field professionals and students. A web link was distributed in a Twitter post by two social media figures in an attempt to reach out to as many potential respondents as possible. This helped improve response rate significantly. The survey was administered via an online survey tool (SurveyMonkey.com, Palo Alto, CA, USA) allowing anonymous responses and voluntary participation. The surveys were available online for a period of three months. To improve response rate, an incentive of $\$ 5$ Starbucks $^{\mathrm{TM}}$ gift cards were offered to 20 participants chosen randomly after responses were collected. Only three participants signed up for the gift cards, which were sent to their e-mail addresses. Subsequently, data was downloaded to a Microsoft Excel spreadsheet and SPSS software was used to run the appropriate statistical analyses.

\section{Data Analysis}

In order to evaluate the research questions, an $\alpha$ level of 0.05 was employed. Descriptive statistics along with t-tests and multiple regression analysis was used. A table of descriptive statistics and zero order correlations for all variables is provided as shown in Table 3. The first research question $\left(\mathrm{RQ}_{1}\right)$ involves descriptive statistics including means, medians and standard deviations which are reported for the three scales of the Maslach Burnout Inventory and compared to existing norms for medical professionals using a series of three one-sample t-tests for the three subscales. To address the second research question $\left(\mathrm{RQ}_{2}\right)$, a simultaneous multiple regression analysis was performed for each of the three MBI subscales utilizing the five control variables and the key predictor (country) in the model. The $R^{2}$ was used to gauge the proportion 
of variation in levels of burnout that the set of variables explains with similar analyses for the other subscales. To address the third research question $\left(\mathrm{RQ}_{3}\right)$, three sequential multiple regression analyses were performed predicting the scores of each subscale separately. In Block 1, the five control variables were entered. In Block 2 , the key predictor (country) was entered. The change in $R^{2}\left(\Delta R^{2}\right)$ and its level of significance was used to answer the research question. The results for both $\mathrm{RQ}_{2}$ and $\mathrm{RQ}_{3}$ are summarized as shown in Tables 4,5 and 6 . 


\section{CHAPTER 3: RESULTS}

The purpose of the study was to assess the burnout experienced by Saudi Arabian dental residents studying abroad through the means of the MBI survey tool by assessing the three dimensions of burnout, Emotional Exhaustion, Depersonalization and Personal Achievement. The assessment results are compared to other medical professionals results in research question number one. In research question number two and three, subscale scores from each of the three dimensions of the MBI are examined via multiple regression analyses to determine which predictors account for unique variation in the indicators of burnout.

\section{Demographics}

A total of 93 residents responded to the survey. The number of complete responses was 87 . Over two-thirds (68.8\%) of respondents were studying in the United States while almost onethird (31.2\%) of the respondents were studying in the United Kingdom. Male respondents comprised $58.1 \%$ of the sample while $41.9 \%$ were female. More respondents were married (64.5\%) than single (35.5\%). Prior work experience, specialty and hours of work per week demographics are shown in Table 2. Most respondents had 1-2 years of prior work experience before beginning their postgraduate programs abroad. Respondents from a wide range of specialties participated in the survey, where Fixed and Removable Prosthodontics residents were the most numerous at $21.5 \%$ while Oral Medicine residents were the fewest (2.2\%). Most of the sample reported being dual sponsored by the Saudi Cultural Mission and an employer. Over a quarter of the sample reported a high number of work hours per week where they were required to work 51 hours per week in program related activities and requirements. 
Table 2

| Demographic Data

\begin{tabular}{|c|c|c|c|c|c|}
\hline Country & $\%$ & $n$ & Specialty & $\%$ & $n$ \\
\hline UK & 31.2 & 29 & Endodontics & 12.9 & 12 \\
\hline USA & 68.8 & 64 & Fixed and removable prosthodontics & 21.5 & 20 \\
\hline Gender & $\%$ & $n$ & Orthodontics & 12.9 & 12 \\
\hline Female & 41.9 & 39 & Oral and maxillofacial surgery & 3.2 & 3 \\
\hline Male & 58.1 & 54 & Advanced education in general dentistry & 9.7 & 9 \\
\hline Sponsorship status & $\%$ & $n$ & Oral medicine & 2.2 & 2 \\
\hline $\begin{array}{l}\text { SACM/Employer only or No } \\
\text { sponsor }\end{array}$ & 30.1 & 28 & Operative and Restorative dentistry & 11.9 & 11 \\
\hline Dual sponsorship & 69.9 & 65 & Periodontics & 5.4 & 5 \\
\hline Marital status & $\%$ & $n$ & Pedodontics & 8.6 & 8 \\
\hline Married & 64.5 & 60 & Oral and maxillofacial Radiology & 4.3 & 4 \\
\hline Single & 35.5 & 33 & Other & 7.5 & 7 \\
\hline Prior work experience & $\%$ & $\boldsymbol{n}$ & Hours of work per week & $\%$ & $n$ \\
\hline Less than 1 year & 18.3 & 17 & Less than 10 hours per week & 5.4 & 5 \\
\hline More than 1 year but less than 2 & 25.8 & 24 & 11-20 hours per week & 6.5 & 6 \\
\hline More than 2 years but less than 3 & 26.9 & 25 & 21-30 hours per week & 12.9 & 12 \\
\hline More than 3 years but less than 4 & 11.8 & 11 & 31-40 hours per week & 16.1 & 15 \\
\hline More than 4 years but less than 5 & 8.6 & 8 & 41-50 hours per week & 32.3 & 30 \\
\hline \multirow[t]{2}{*}{ More than 5 years } & \multirow[t]{2}{*}{8.6} & \multirow[t]{2}{*}{8} & 51-60 hours per week & 10.8 & 10 \\
\hline & & & More than 60 hours per week & 16.1 & 15 \\
\hline
\end{tabular}

$(\mathrm{n}=$ all participants $=93)$

\section{Reliability}

Reliability was evaluated using Cronbach's alpha for the three MBI-HSS (MP) scales yielding coefficients of 0.819 for Emotional Exhaustion (EE), 0.642 for Depersonalization (DEP) and 0.708 for Personal Achievement (PA). That the reliability for DEP was below .70 suggests a potential threat to statistical conclusion validity for analyses involving depersonalization, a limitation to be noted in the discussion, as well.

\section{Results Regarding Research Question One}

To address the first research question, as to the level of burnout, one-sample t-test analyses were performed, employing an alpha level of .05 to compare the means of Saudi dental residents to that of the medical profession for the three MBI scales. The means of the medical professionals $(2.466,1.424$, and 4.566 for emotional exhaustion, depersonalization, and personal accomplishment, respectively) were obtained from the Maslach Burnout Inventory Manual 
(Maslach, Jackson \& Leiter, 2016). There is evidence to suggest a statistically significant difference between the means of Saudi Arabian dental residents $(M=2.73, S D=1.20)$ and the medical professionals population means in Emotional Exhaustion $(p=.043)$. Specifically, we are $95 \%$ confident that the dental residents are at least .009 and at most .52 points higher in emotional exhaustion. However, there was insufficient evidence to suggest a statistically significant difference in Depersonalization $(p=.860)$ and Personal Achievement $(p=.510)$, based on the dental residents' sample statistics $(M=1.45, S D=1.16)$ and $(M=4.41, S D=.96)$

respectively.

Table 3

Descriptive Statistics and Zero Order Correlations

\begin{tabular}{|c|c|c|c|c|c|c|c|c|c|c|c|}
\hline & 1. & 2. & 3. & 4. & 5. & 6. & 7. & 8. & 9. & $\bar{M}$ & SD \\
\hline $\begin{array}{l}\text { 1. Country }(1= \\
\text { USA, } 0=\text { UK) }\end{array}$ & - & - & - & - & - & - & - & - & - & 0.68 & 0.47 \\
\hline $\begin{array}{l}\text { 2. Hours of } \\
\text { Work/week }\end{array}$ & .15 & - & - & - & - & & - & - & - & 4.63 & 1.62 \\
\hline $\begin{array}{l}\text { 3. Sponsorship } \\
\text { Status ( } 1=\text { SACM* } \\
\text { \& Employer, } 0= \\
\text { SACM only) }\end{array}$ & .16 & -.07 & - & - & - & - & - & - & - & 0.24 & 0.43 \\
\hline $\begin{array}{l}\text { 4. Marital Status } \\
\text { (1=Married, } 0= \\
\text { Single) }\end{array}$ & -.05 & -.01 & -.03 & - & - & - & - & - & - & 0.64 & 0.49 \\
\hline $\begin{array}{l}\text { 5. Prior Work } \\
\text { Experience }\end{array}$ & -.19 & -.04 & -.07 & .16 & - & - & - & - & - & 2.89 & 1.45 \\
\hline $\begin{array}{l}\text { 6. Gender }(1= \\
\text { Female, } 0=\text { Male })\end{array}$ & -.12 & -.19 & -.03 & $-.22 * *$ & -.13 & - & - & - & - & 0.42 & .50 \\
\hline $\begin{array}{l}\text { 7. Emotional } \\
\text { Exhaustion (EE) }\end{array}$ & .27 & $.23 * *$ & .20 & -.08 & .04 & .19 & - & - & - & 2.73 & 1.20 \\
\hline $\begin{array}{l}8 . \\
\text { Depersonalization } \\
\text { (DP) }\end{array}$ & .02 & -.02 & .13 & -.00 & .01 & .07 & $.55^{* * *}$ & - & - & 1.45 & 1.16 \\
\hline $\begin{array}{l}\text { 9. Diminished } \\
\text { Personal } \\
\text { Accomplishment } \\
\text { (PA) }\end{array}$ & -.02 & .11 & .58 & .010 & .05 & $-.24 * *$ & -.13 & -.10 & - & 4.41 & 0.96 \\
\hline
\end{tabular}

$(\mathrm{n}=87)$

*SACM $=$ Saudi Arabian Cultural Mission

$* *$ Correlation is significant at the 0.05 level (2-tailed)

$* * *$ Correlation is significant at the 0.01 level (2-tailed) 


\section{Results Regarding Research Questions Two and Three}

Multiple regression analyses were conducted to address research questions two and three regarding the proportion of variation accounted for by the set of six predictors and which predictors account for unique variation in the levels of burnout. Tables 4,5 and 6 summarize the results of analyses for the three subscales, respectively.

Emotional exhaustion. In Table 4, the multiple regression model for emotional exhaustion (EE) with all six predictors was statistically significant and explained $18.8 \%$ of the variation, $F(6$, $80)=3.087, p=.009, R^{2}=.188$. Whereas the set of five variables in the first block accounted for $16.8 \%$ of the variance, knowing the country in which the student was a dental resident explained an additional $2.0 \%$ of the variance in EE. This increase, however, was not statistically significant, $F(1,80)=1.954, p=.166$. Three of the predictors accounted for unique variation in levels of EE. The unstandardized regression coefficient for hours worked per week, $b=.229, t(80)=2.993, p=$ .004 , indicates that for each additional unit increase of the predictor (10 hours increments), EE scores increased by .229 points, controlling for other predictors. Of more interest was the coefficient associated with Sponsorship, $b=.712, t(80)=2.491, p=.015$, where being sponsored is associated with an increase of .712 points on the EE scale while controlling for other predictors. Once other variables are taken into account, gender was a statistically significant predictor for the EE scale, as well. On average, the EE scores of females (coded 1) were .550 points higher than males (coded 0$), b=.550, t(80)=2.091, p=040$. Those studying in the US (coded 1$)$ had lower EE scores, on average, than those studying in the UK (coded 0), but the difference was not statistically significant, $b=-.383, p=.166$. 
Table 4

Sequential Multiple Regression Results Predicting Maslach Burnout Inventory (MBI) Emotional Exhaustion Subscale Scores

\begin{tabular}{|l|l|l|l|l|l|l|l|}
\hline & $b$ & $S E_{b}$ & $\beta$ & $t$ & $p$ & $R^{2}$ & $\Delta R^{2}$ \\
\hline Block 1 & & & & & & .168 & .168 \\
\hline Hours worked per week & .229 & .077 & .311 & 2.993 & .004 & & \\
\hline Sponsorship (1= yes) & .712 & .286 & .256 & 2.491 & .015 & & \\
\hline Gender (1= female) & .550 & .263 & .226 & 2.091 & .040 & & \\
\hline Marital Status (1= married) & -.097 & .260 & -.039 & -.374 & .709 & & \\
\hline Years of prior work & .065 & .087 & .079 & .748 & .457 & & \\
experience & & & & & & & \\
\hline Block 2 & & & & & & .188 & .020 \\
\hline Country (1= US) & -.383 & .274 & -.150 & -1.398 & .166 & & \\
\hline Note 1. Full & & & & & & & \\
\hline
\end{tabular}

Notes: 1. Full Model: $F(6,80)=3.087, p=.009, R^{2}=.188$

2. Change: $F(1,80)=1.954, p=.166, R^{2}=.020$

Depersonalization. In Table 5, the multiple regression model for depersonalization (DEP) the set of six predictors was statistically significant but explained just $2.2 \%$ of the variation, $F(6,80)=.297, p=.937, R^{2}=.022$. Whereas the set of five variables in the first block accounted for $2.1 \%$ of the variance, knowing the country in which the student was a dental resident explained less than $1 \%$ more of the variance in DEP. This increase was not statistically significant, $F(1,80)=0.039, p=.844$. None of the predictors accounted for unique variation in levels of DEP. Those studying in the US (coded 1) had higher DEP scores, on average, than those studying in the UK (coded 0), but the difference was not statistically significant, $b=.057$, $p=.844$ 
Table 5

Sequential Multiple Regression Results Predicting Maslach Burnout Inventory (MBI)

Depersonalization Subscale Scores

\begin{tabular}{|l|l|l|l|l|l|l|l|}
\hline & $b$ & $S E_{b}$ & $\beta$ & $t$ & $p$ & $R^{2}$ & $\Delta R^{2}$ \\
\hline Block 1 & & & & & & .021 & .021 \\
\hline Hours worked per week & .002 & .081 & .002 & .022 & .983 & & \\
\hline Sponsorship (1= yes) & .343 & .304 & .127 & 1.129 & .262 & & \\
\hline Gender (1= female) & .187 & .280 & .079 & .668 & .506 & & \\
\hline Marital Status (1= married) & .036 & .276 & .015 & .129 & .898 & & \\
\hline Years of prior work & .020 & .092 & .026 & .222 & .825 & & \\
experience & & & & & & & \\
\hline Block 2 & & & & & & .022 & .000 \\
\hline Country (1= US) & .057 & .291 & .023 & .197 & .844 & & \\
\hline Note 1. Full & & & & & & & \\
\hline
\end{tabular}

Notes: 1. Full Model: $F(6,80)=.297, p=.937, R^{2}=.022$

2. Change: $F(1,80)=0.039, p=.844, R^{2}=.000$

Personal accomplishment. In Table 6, the multiple regression model for personal accomplishment (PA) with all six predictors was not statistically significant and explained $7.8 \%$ of the variation, $F(6,80)=1.128, p=.354, R^{2}=.078$. Whereas the set of five variables in the first block accounted for $7.0 \%$ of the variance, knowing the country in which the student was a dental resident explained less than $1 \%$ of the variance in PA. This increase, then, was not statistically significant, $F(1,80)=.686, p=.410$. Gender was the only predictor that accounted for unique variation in levels of PA. On average, the PA scores of females (coded 1) were .490 points lower than males (coded 0$), b=-.490, t(80)=-2.181, p=.032$. Those studying in the US (coded 1) had lower PA scores, on average, than those studying in the UK (coded 0), but the difference was not statistically significant, $b=-.193, p=.410$. 
Table 6

Sequential Multiple Regression Results Predicting Maslach Burnout Inventory (MBI) Personal Achievement Subscale Scores

\begin{tabular}{|c|c|c|c|c|c|c|c|}
\hline 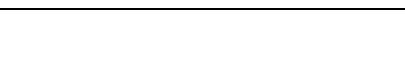 & $b$ & $S E_{b}$ & $\beta$ & $t$ & $p$ & $R^{2}$ & $\Delta R^{2}$ \\
\hline Block 1 & & & & & & .070 & .070 \\
\hline Hours worked per week & .050 & .065 & .085 & .772 & .443 & & \\
\hline Sponsorship $(1=$ yes $)$ & .162 & .244 & .073 & .663 & .509 & & \\
\hline Gender $(1=$ female $)$ & -.490 & .225 & -.252 & -2.181 & .032 & & \\
\hline Marital Status (1= married) & -.101 & .222 & -.051 & -.457 & .649 & & \\
\hline $\begin{array}{l}\text { Years of prior work } \\
\text { experience }\end{array}$ & .013 & .074 & .019 & .172 & .864 & & \\
\hline Block 2 & & & & & & .078 & .008 \\
\hline Country $(1=$ US $)$ & -.193 & .234 & -.095 & -.828 & .410 & & \\
\hline \multicolumn{8}{|c|}{ Notes: 1 . Full Model: $F(6,80)=1.128, p=.354, R^{2}=.078$} \\
\hline
\end{tabular}




\section{CHAPTER 4: DISCUSSION}

The findings of this study aligned with those of previous research in terms of burnout prevalence in dental postgraduate students. Nettam et al. (2018) and Divaris et al. (2012a) reported similar positive correlation between stress and burnout by employing different methodologies. However, some results suggested new information when compared with previous research findings. Nettam et al. (2018) found no significant differences between males and females in reporting burnout.

Multiple studies suggested higher burnout on the three MBI scales in physicians (Soler et al., 2008) and health care staff (Piko, 2008). The sample mean for the Emotional Exhaustion MBI scale was significantly different than the medical professionals population mean provided by the MBI manual. The sample means were significantly higher in EE compared to the medical professional means. This suggests that Saudi Arabian dental residents experience high burnout due to emotional exhaustion when compared to other medical professionals. The Depersonalization and Personal Achievement scales means were not found to be significantly different between the two.

In the multiple regression analysis, EE model was found to vary significantly according to hours of work per week, sponsorship status and gender. This suggests that increased workload contributes to higher burnout. Interestingly, dual income residents from a sponsor job and the Saudi Cultural Mission experienced more emotional exhaustion than their SACM only single income or self sponsored counterparts. This could be explained by the added pressure from employers on residents to meet multiple requirements and achievements before returning to the workforce. Moreover, it is suggested that females experienced more emotional exhaustion and 
less sense of personal achievement than their male counterparts. This aligns with a study by Minamizono et al. (2019) suggesting that female nurses in Japan reported higher stress and subsequent intention to leave careers due to assigned gender roles and socio-cultural pressures. Balancing work and family life could potentially contribute to added pressures on females in health care. Interestingly, Marital status and prior work experience did not explain any variance or difference in the analyses. This differs from findings by Al-Shayea (2014) where married students were found to report less stress and burnout compared to their single counterparts.

\section{Assumptions and Limitations}

Statistical assumptions include those underlying the use of multiple regression analysis such as: normality, linearity, homoscedasticity, and independence of the error terms. A methodological limitation of self-reporting assumes complete transparency in responding to the survey. However, the effect of this assumption is assumed to have been minimized by the anonymous and voluntary nature of this study. Moreover, responses from residents in different dental specialty programs limit the equal distribution of subjects across the specialty type category. This study is also limited by the concurrent political circumstances of the program countries and Saudi Arabia. It's also important to note that generalizability or external validity is limited to the characteristics of the participants. Furthermore, some dental specialties were not included in this study due to the nature of these programs being only indirectly interactive with patients, e.g., oral histology and oral pathology.

Reliability testing of the MBI scales revealed sufficient internal consistency for EE and PA but not for DEP. This can be related to the number of items in the scale. DEP has 5 items only while EE and PA have 9 and 8 items respectively. This limitation has likely affected the multiple regression results pertaining to DEP where none of the individual predictors was 
statistically significant. This could also be explained by another limitation this study faced where the number of complete responses were insufficient to detect subtle effects. Increasing the incentive promised to participants or contacting residency program directors requesting recruitment of their residents in a formal way where they set aside time for residents to complete the survey during working hours could have increased the response rate. However, due to time and financial constraints and the researcher's limited social network in dental schools in the US and the UK, these methods were not feasible. There was a difficulty in reaching out to all residents due to variation in physical location between different countries, schools and specialties. This results in limited statistical power to the analysis and poses a threat to statistical conclusion validity.

\section{Suggestions for Further Research}

More investigation is needed to evaluate the differences in reported burnout in the excluded specialties and across various program types, e.g., fellowship and $\mathrm{PhD}$ programs, to broaden our understanding of this phenomenon and inform future residents who are opting to pursue postgraduate studies. Although this is a comparative study, it is imperative to adopt a longitudinal study design to allow for causal inferences in understanding how burnout progresses over time in health care professionals and the effect it could have on patient care and medical errors. Cultural and social norms affecting female professionals should be explored to ensure better awareness in this critically affected subgroup, in particular. Moreover, qualitative study designs utilizing open ended questions could be used to elicit, for example, participants' experience as a resident, including their feelings related to burnout and the expectations they perceive their sponsors to have for them during their programs. 


\section{Recommendations and Conclusion}

Burnout is a serious problem facing health care professionals. International students are at an even higher risk potentially due to change in social and professional environment, cultural differences and financial limitations. The following presents some suggestions for problems facing health care professionals.

For dental residents, it is recommended to find ways to reduce stress and sequentially burnout by time management measures, relaxation and leisure activities. Residents need to be aware of the symptoms of burnout and educate themselves about the signs and how to combat them as early as possible. They should not be afraid to seek help or guidance from their supervisors or program directors.

Residency programs can improve residents' experiences by providing seminars to educate residents about burnout and plan regular leisurely activities with possible credits towards their degrees to entice residents into participation. Female residents were found to experience higher burnout in this study sample. This was supported by results another study as well (Minamizono, 2019). Therefore, females should be considered a critical group to be further encouraged to de-stress and express their perception of personal achievements with faculty or counselors as a part of their official programs. A required psychology course can be offered as a part of the dental residency program to allow dental residents to explore a variety of psychological issues that could affect their careers, their patients and patient care. Another recommendation for dental programs would be to provide online counseling for health care specialties students. This option provides convenience for these students who often have rotations in multiple locations (e.g. clinics, hospitals and campuses) so that they can access psychological care online anywhere. 
The Saudi Arabian sponsors investment in the medical and dental health care professionals can benefit from providing these individuals with a good experience during their studies abroad. Alleviating burnout in residents can be achieved by simplifying the necessary procedures and paperwork required to maintain sponsorship. Saudi Arabian academic advisors can play an integral role in providing mental health support to those in need of it. These measures should enhance their academic experience and subsequently their professional performance once they return to practice in Saudi Arabia. It can also help in retaining health care professionals and their relationships with co-workers and staff to enhance the health care services they provide the Saudi Arabian patient population.

Burnout is a multifactorial issue facing health care specialty students. It can be reduced through the efforts of all the stakeholders involved in the students' education process. It is imperative to further explore this phenomenon and employ a multitude of ways to overcome this issue to aim for better mental health care and psychological stability for health care professionals leading to elevated performance and optimum experiences for patients seeking their services and expertise. 


\section{REFERENCES}

ADEA. (2018). Policy. American Dental Education Association.

Ahmad, F. A., Karimi, A. A., Alboloushi, N. A., Al-Omari, Q. D., AlSairafi, F. J., \&

Qudeimat, M. A. (2017). Stress level of dental and medical students: comparison of effects of a subject-based curriculum versus a case-based integrated curriculum. Journal of Dental Education, 81(5), 534-544.

Al-Shayea, E. I. (2014). Perceived Depression, Anxiety and Stress Among Saudi Postgraduate Orthodontic Students: A Multi-Institutional Survey. Pakistan Oral \& Dental Journal, 34(2).

Al-Sowygh, Z. H. (2013). Academic distress, perceived stress and coping strategies among dental students in Saudi Arabia. The Saudi Dental Journal, 25(3), 97-105.

Assael, L. (2017). Current status of postdoctoral and graduate programs in dentistry. Journal of Dental Education, 81(8), eS41-eS49.

Andre, A., Pierre, G. C., \& McAndrew, M. (2017). Quality of Life Among Dental Students: A Survey Study. Journal of Dental Education, 81(10), 1164-1170.

Baum, A. (1990). "Stress, Intrusive Imagery, and Chronic Distress," Health Psychology, 9(6), 653-675.

Divaris, K., Lai, C. S., Polychronopoulou, A., Eliades, T., \& Katsaros, C. (2012). Stress and burnout among Swiss dental residents. Schweizer Monatsschrift fur Zahnmedizin, 122(78), 610-615. 
Divaris, K., Polychronopoulou, A., Taoufik, K., Katsaros, C., \& Eliades, T. (2012). Stress and burnout in postgraduate dental education. European Journal of Dental Education, 16(1), $35-42$.

Elani, H. W., Allison, P. J., Kumar, R. A., Mancini, L., Lambrou, A., \& Bedos, C. (2014). A systematic review of stress in dental students. Journal of Dental Education, 78(2), 226242.

Harrison, P. L., Shaddox, L. M., Garvan, C. W., \& Behar-Horenstein, L. S. (2016). Wellness among dental students: an institutional study. Journal of Dental Education, 80(9), 11191125.

Maslach, C., Jackson, S. E., Leiter, M. P., Schaufeli, W. B., \& Schwab, R. L. (1981). Maslach Burnout Inventory [Third Edition Manual]. Retrieved from http://0search.ebscohost.com.pacificatclassic.pacific.edu/login.aspx?direct=true $\& \mathrm{db}=\mathrm{mmt} \& \mathrm{AN}=$ test.1996\&site $=$ ehost-live \&CUSTID $=$ s 8968023

Maslach, C., \& Leiter, M. P. (2016). Understanding the burnout experience: Recent research and its implications for psychiatry. World Psychiatry, 15(2), 103-111. doi:10.1002/wps.20311

Maslach, C., Jackson, S. E., \& Leiter, M. P. (2016). Maslach burnout inventory: Manual. Place of publication not identified: Mind Garden.

Minamizono, S., Nomura, K., Inoue, Y., Hiraike, H., Tsuchiya, A., Okinaga, H., \& Illing, J. (2019). Gender Division of Labor, Burnout, and Intention to Leave Work Among Young Female Nurses in Japan: A Cross-Sectional Study. International Journal of Environmental Research and Public Health, 16(12), 2201. doi:

10.3390/ijerph16122201 
Mind Garden (2018). Maslach Burnout Inventory - Human Services Survey for Medical Personnel (MBI-HSS (MP)) - Assessments, Tests. Retrieved from www.mindgarden.com/315-mbi-human-services-survey-medical-personnel.

Murphy, R. J., Gray, S. A., Sterling, G., Reeves, K., \& DuCette, J. (2009). A Comparative Study of Professional Student Stress. Journal of Dental Education, 73(3), 328-337.

Nettam V., Mandava, P., SankarSingaraju, G., Ganugapanta, V. R., \& Yelchuri, H. (2018). Comparison of stress, burnout and its association among postgraduate orthodontic and undergraduate students in India. Indian Journal of Dental Sciences, 10(2), 66.

Piko, B. (2006). Burnout, role conflict, job satisfaction and psychosocial health among Hungarian health care staff: A questionnaire survey. International Journal of Nursing Studies, 43(3), 311-318.

Soler, J., Yaman, H., Esteva, M., Dobbs, F., Asenova, R., \& Katic, M., ...Ungan, M. (2008). Burnout in European family doctors: the EGPRN study. Family Practice, 25(4), 245-265. doi: 10.1093/fampra/cmn038

Vinson, L. A., Nies, J. Q., Jones, J. E., Tomlin, A. M., Jackson, R. D., \& Sanders, B. J. (2016). Stress and the pediatric dental resident: Contributing factors and coping mechanisms. Journal of Education and Ethics in Dentistry, 6(2), 61.

Yusoff, Y. M. (2011). International Students' Adjustments in Higher Education: Relation Between Social Support, Self-efficacy, and Socio-Cultural Adjustment. Australian Journal of Business and Management Research, 1(1), 1. 


\section{APPENDIX A: ONLINE SURVEY CONSENT FORM}

You are invited to participate in a research study conducted by Amal Asiri BDS from the University of the Pacific. You were selected to participate in this study because you are a Saudi Arabian dental resident enrolled in a postgraduate program in the USA or UK. The purpose of this research study is to explore factors that may account for variation in the emotional experiences of residents while attending dental clinical postgraduate programs outside Saudi Arabia. If you agree to take part in this study, a survey will be presented online that you are to respond to anonymously. The survey is designed to take at most 30 minutes to complete. This survey will ask about demographic information, program sponsorship status, program details and your personal feelings during the residency experience.

You may not directly benefit from this research; however, we hope that your participation in the study may provide insights about the experiences of Saudi Arabian dental residents studying in the UK and the USA. Twenty respondents will be chosen at random to receive a $\$ 5$ Starbucks ${ }^{\mathbf{T M}}$ gift card at the end of the data collection period. We believe there are no known risks associated with this research study; however, as with any online related activity the risk of a breach of confidentiality is always possible. To the best of our ability your answers in this study will remain confidential. We will minimize any risks by anonymous data collection stored in password-protected computers. Your participation in this study is completely voluntary and you can withdraw at any time. You are free to skip any question that you choose.

If you have questions about this project or if you have a research-related problem, you may contact the researcher, Amal Asiri at +1 (415) 542-6557 or a_asiri@u.pacific.edu or her research advisor, Dr. Rachelle Kisst Hackett at +1 (209) 946-2678 or rhackett@pacific.edu . If you have any questions concerning your rights as a research subject, you may contact the University of the Pacific, Human Subjects - Institutional Review Board (IRB) at:

(209) 946-3903

irb@pacific.edu

Knoles Hall, 2nd Floor, Room 204

By clicking "I agree" below you are indicating that you are at least 18 years old, have read and understood this consent form and agree to participate in this research study. Please print a copy of this page for your records.

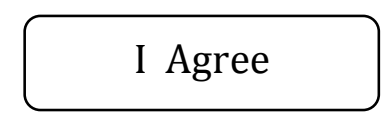

I Do Not Agree 


\section{APPENDIX B: DEMOGRAPHIC QUESTIONNAIRE}

Directions: This survey will be used to gather information from Saudi Arabian dental residents to better understand their experiences while enrolled in post-graduate programs abroad. There are no wrong or right answers. What is important, however, is that you respond as honestly and completely as possible. Therefore, no personally identifying information is asked and the results from the anonymous survey will be presented in the aggregate. Any information provided will be strictly confidential for the purposes of this research. Please answer the following questions:

\section{Country of program:}

1- USA

2- UK

\section{Gender:}

1- F

2- $\mathrm{M}$

\section{Marital status:}

1- Married

2- Single

Sponsorship status:

1- Saudi Arabian Cultural Mission (SACM) only

2- Employer and Saudi Arabian Cultural Mission (SACM)

\section{Employer in Saudi Arabia:}

1- University

2- Ministry of health

3- Armed Forces

4- National guard

5- Other (please specify):

6- I prefer not to answer

Work experience prior to program enrollment:

$1-<1$ year

2- 1 year

3- 2 years

4- 3 years

5- 4 years

6- 5 years or more

Program specialty:

1- Endodontics

2- Fixed and removable prosthodontics

3- Oral and oromaxillofacial surgery

4- Orthodontics

5- Pedodontics

6- Periodontics

7- Other (please specify):

Length of the program you are enrolled in:

$1-1$ year

2- 2 years 
3- 3 years

4- 4 years

5- 5 years or more

What year of the program are you currently in:

$1-1^{\text {st }}$ year

2- $2^{\text {nd }}$ year

3- $3^{\text {rd }}$ year

4- $4^{\text {th }}$ year

5- $5^{\text {th }}$ year or more

Hours of work per week related to your study (hr/wk):

1- Less than $10 \mathrm{hr} / \mathrm{wk}$

2- 11-20 hr/wk

3- 21-30 hr/wk

4- $31-40 \mathrm{hr} / \mathrm{wk}$

5- $41-50 \mathrm{hr} / \mathrm{wk}$

6- 51-60 hr/wk

7- More than $60 \mathrm{hr} / \mathrm{wk}$

What's the name of the school you are enrolled in?

1 -

2- I prefer not to answer 